\section{The presentation, clinical features, complications, and treatment of congenital dacryocystocele}

R Davies ${ }^{1}$, WJ Watkins ${ }^{2}$, S Kotecha ${ }^{3}$ and P Watts ${ }^{4}$

measures may be sufficient in cases of uncomplicated dacryocystocele.

Eye (2018) 32, 522-526; doi:10.1038/eye.2017.235; published online 27 October 2017

\section{Introduction}

Nasolacrimal duct obstruction (NLDO) causing epiphora and mucopurulent discharge in children, affects $\sim 1.2-20 \%$ of newborns. ${ }^{1-4}$ Development of a dacryocystocele in an infant with the clinical features of NLDO is rare. ${ }^{5}$ A dacryocystocele is a cystic bluish swelling that can develop in the medial canthal area of the newborn within the first 12 weeks of life. ${ }^{6,7}$ It is due to accumulation of fluid trapped within the lacrimal sac, which is blocked distally at the nasolacrimal duct and proximally at the common canalicular duct. ${ }^{8-10}$ Stagnation of tears within the lacrimal sac can predispose to developing dacryocystitis, ${ }^{11}$ with current literature reporting this to be present in between $18^{12}$ and $75 \%^{8}$ of cases. Dacryocystoceles may also extend intra-nasally as cysts and cause respiratory compromise, ${ }^{13-15}$ as newborns are obligate nasal breathers. Intranasal cysts have been reported in up to $100 \%$ of cases where endoscopy is performed. ${ }^{16}$ The reported prevalence of dacryocystoceles in a well defined population of the United States of America has been reported to be 1 in 3884 live births estimated over a 20 year period; 11 however, such data are lacking in the United Kingdom. The condition is seen predominantly in females, $7,10,11,17$ Caucasians, ${ }^{11}$ and is more commonly unilateral. $7,11,17-19$

The treatment of congenital dacryocystocele remains controversial. 6,8,15 Dacryocystoceles have been reported to resolve spontaneously by birth in instances where they have been detected
Received: 16 May 2017 Accepted in revised form: 14 August 2017 Published online: 27 October 2017
${ }^{1}$ Department of
Ophthalmology, University
Hospital of Wales, Cardiff,

Correspondence:

Ophthalmology, University Hospital of Wales, Cardiff $4 X W$, UK

E-mail: patrick.watts@

wales.nhs.uk

Conclusions Congenital dacryocystocele is a rare presentation in the United Kingdom. Dacryocystitis and respiratory compromise commonly complicate a dacryocystocele. The use of digital massage as an early intervention is advocated and conservative 
on antenatal imaging in utero; ${ }^{20,21}$ however, the frequency of natural resolution of the condition in the post-natal period without treatment is not known. It is therefore suggested by some authors that the treatment of an uncomplicated dacryocystocele should be conservative, $6,7,12,18$ while others advocate early intervention ranging from nasolacrimal duct probing to endoscopic marsupialisation. 5,8,15,19,22 Treatment of congenital dacryocystitis complicating a dacryocystocele is also controversial with some suggesting early surgical intervention 7,8,16,23,24 and others suggesting initial treatment with antibiotics. ${ }^{25,26}$ There have been reports of probing induced bacteraemia without prior antibiotic cover. $^{27}$

This primary purpose of this study is to determine the incidence of congenital dacryocystoceles in the United Kingdom along with patient demographics including gender, race and laterality. In addition the number of cases that resolve spontaneously or with intervention, whether it is massage alone or in combination with surgery, and those complicated by either dacryocystitis or intranasal cysts will be reported. This will provide valuable information to guide clinicians on the management of this rare condition and its complications.

\section{Materials and methods}

This is a prospective observational study of incident cases of congenital dacryocystocele presenting between September 2014 and October 2015 within the UK. All infants $<3$ months of age diagnosed with a cystic swelling in the medial canthal area reported to be a dacryocystocele were included. Infants diagnosed with congenital dacryocystitis, with or without a previous history of a cystic swelling were also included. Cases presenting with epiphora or a mucopurulent discharge without a medial canthal swelling were excluded.

Incident cases were ascertained through the British Ophthalmological Surveillance Unit (BOSU) reporting card system. An initial questionnaire was then sent to the reporting ophthalmologist along with a follow-up questionnaire at a 6month interval. The questionnaires were designed in conjunction with the British Ophthalmological Surveillance Unit (BOSU) committee. Ethical approval was obtained through the National Research Ethics Society in the United Kingdom.

The initial questionnaire included the patients' date of birth and gender, to assist with identification of the correct patient for a follow-up questionnaire. We also gathered data on mode of delivery and stage of gestation. With regards to the dacryocystocele, we collected data on laterality, symptoms of nasal obstruction, presence of cellulitis, presence of a lump and its colour, pyrexia and finally the treatment undertaken.
In the follow on questionnaire we collected data on time taken to resolution, recurrence and whether the patient had been discharged or remained under followup. The statistical methods were used were the Chisquared test and non-parametric analysis to identify differences between groups. SPSS 22 (IBM Corp. Released 2013. IBM SPSS Statistics for Windows, Version 22.0. Armonk, NY, USA) was used for this analysis.

\section{Results}

A total of 50 cases were reported over the study period. One case was outside our study criteria being older than 3 months at diagnosis and therefore excluded, thus leaving a total of 49 cases. There were 911299 births (office of national statistics) over the same time period giving an incidence of 1 in 18597 . There was a 71\% $(35 / 49)$ response to the initial questionnaire. The average age at diagnosis was 16.94 days (0-64 days, Figure 1$)$. There were 3 bilateral cases giving rise to 38 dacryocystoceles from 35 patients.

Female cases were slightly more common for $54 \%$ $(19 / 35)$ of patients. Almost all cases were full term, $94 \%$ $(33 / 35)$, with only $3 \%(1 / 35)$ being premature and $3 \%$ $(1 / 35)$ not reported. For mode of delivery $66 \%(23 / 35)$ were born via normal vaginal delivery, $6 \%(2 / 35)$ were assisted with forceps and 11\% (4/35) were born via caesarean section. The remainder the modes of delivery were not reported. There was no association between the mode of delivery and the presence of dacryocystitis. The majority of patients were Caucasian, accounting for $80 \%$

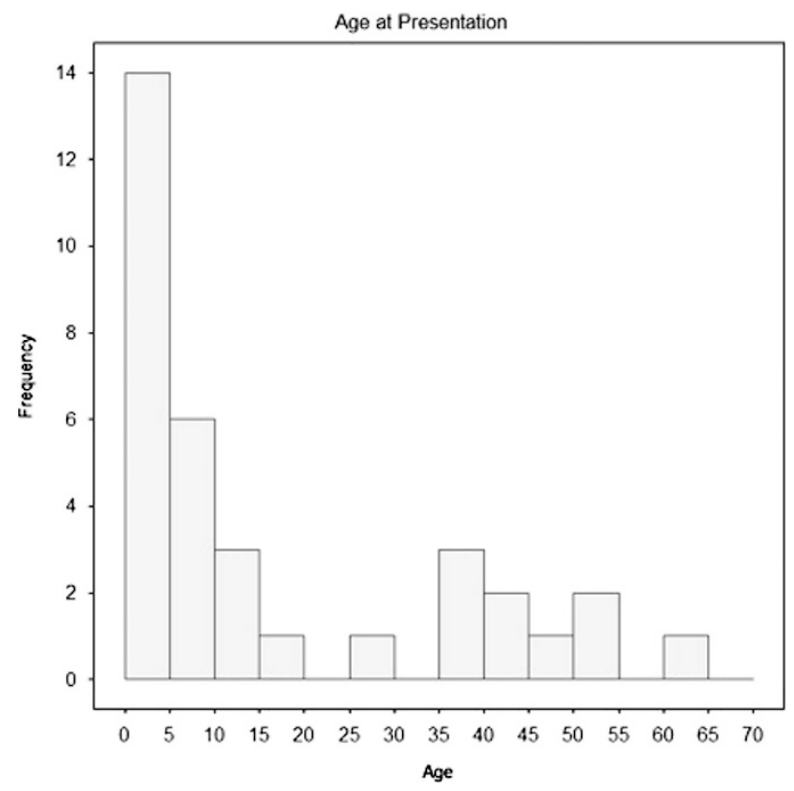

Figure 1 Age in days at presentation. Graph to show distribution of age (days) at presentation. There are 34 cases demonstrated, as the age of one patient was not reported. 
(28/35). Dacryocystoceles were unilateral in 91\% (32/35) of patients, with bilateral cases accounting for the remainder. The right side was more commonly affected accounting for $55 \%(21 / 38)$ of dacryocystoceles.

Dacryocystitis was reported in $49 \%$ of patients $(17 / 35)$. A lump was present in $100 \%$ of dacryocystoceles, $61 \%$ $(23 / 38)$ were reported to be bluish in colour with $26 \%$ $(10 / 38)$ being red. Symptoms of nasal obstruction were reported in $17 \%(6 / 35)$ of patients.

\section{Treatment}

Dacryocystocele $\quad 40 \%(14 / 35)$ of patients had an uncomplicated dacryocystocele (Figure 2). Two of these were bilateral giving rise to 16 uncomplicated dacryocystoceles. Of these $13 \%(2 / 16)$ of dacryocystoceles had no treatment and all spontaneously resolved. Massage was the only form of treatment in 31\% (5/16) of uncomplicated dacryocystoceles and all resolved. Antibiotics were given to $57 \%(8 / 14)$ of patients in addition to or instead of massage ( $2 / 8$ topical alone, $1 / 8$ oral, $3 / 8$ intravenous with $2 / 8$ of unknown type). Two patients $(14 \%-2 / 14)$ underwent surgical intervention with probing of the nasolacrimal duct.

Dacryocystocele complicated by dacryocystitis Dacryocystitis was a complicating factor in 45\% (17/38) of dacryocystoceles or $49 \%$ of patients $(17 / 35)$ overall. All of these were treated with antibiotics (14/17 intravenous and $3 / 17$ oral antibiotics). Surgical intervention was required in $29 \%(5 / 17)$ in the form of probing (3) and endonasal endoscopic decompression (2). Dacryocystitis therefore resolved in $71 \%$ of patients without needing surgical intervention. One probing was necessary to treat a recurrence after medical therapy had been completed.

Dacryocystocele complicated by respiratory distress Approximately $17 \%(6 / 35)$ of patients had signs of nasal obstruction, with $17 \%(1 / 6)$ receiving massage only, $67 \%$ (4/6) having massage and antibiotics (1 intravenous, 1 oral, and 2 of unknown type), with $17 \%$ (1/6) requiring surgical intervention (endoscopic decompression). Two of these patients also had dacryocystitis and for the benefit of analysis they were included in both the dacryocystitis and respiratory distress group.

\section{Overall}

Massage was used in $63 \%(23 / 35)$ of patients and for $14 \%$ $(5 / 35)$ it was the sole form of treatment. There does appear to be a tendency for massage to reduce the need for surgical intervention; however, this was not statistically significant $(P=0.225)$. Antibiotics were given to $77 \%(27 / 35)$ of patients including topical and systemic

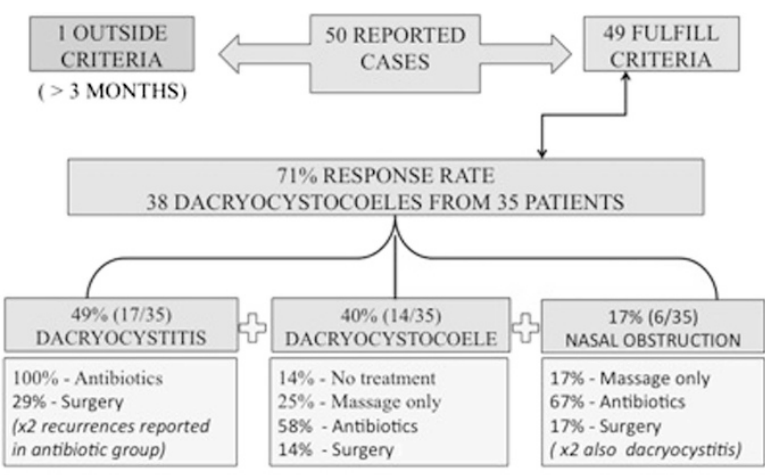

MEAN TIME TO RESOLUTION - 19 DAYS

Figure 2 Summary of cases reported and treatment undertaken. Flowchart demonstrating the number of cases reported and response rate to questionnaire. The summary of treatment for those patients with dacryocystocele alone and those complicated with dacryocystitis or nasal obstruction is also demonstrated.

forms (17 intravenous/10 oral/2 topical only). There was no treatment given to $6 \%(2 / 35)$ of patients. Surgical intervention was required in $23 \%(8 / 35)$ of patients or $26 \%(10 / 38)$ of dacryocystoceles, including probing when acute (3 dacryocystoceles), probing when quiescent (3 dacryocystoceles) and endoscopic decompression and marsupialisation (4 dacryocystoceles). All patients that underwent endoscopy were reported to have intranasal cysts. Patients with red lumps are more likely to require surgery $(P=0.05)$ in keeping with the fact that these are more likely to have dacryocystitis. All dacryocystoceles where a red lump was present $(10 / 38)$ were found to have dacryocystitis. Dacryocystitis was however also reported in cases with blue lumps $(7 / 38)$. There was no significant effect of age at diagnosis with relation to requirement for surgical intervention or outcome.

There were 31 responses to the follow on questionnaire $(63 \%)$. One of which was outside our criteria (older than 3 months) thus excluded, leaving 30 cases. There were 31 dacryocystoceles from these 30 patients ( 1 bilateral). The mean time to resolution was 19 days (1-140 days). There was a recurrence reported in $6 \%(2 / 30)$ of patients, both of which were complicated by dacryocystitis and one required probing. There was one patient who required a repeat probing prior to resolution. The majority of patients were discharged with only $16 \%(5 / 30)$ of patients remaining under follow-up.

\section{Discussion}

This is the first national study of dacryocystoceles in the UK. We report an incidence of 1 in 18597 live births for congenital dacryocystocele. Most cases were diagnosed within the first 15 days of life. There is a slight female 
preponderance (54\%). The majority of cases are unilateral (91\%) and almost half of cases appear to be complicated by dacryocystitis. Evidence of nasal obstruction was present in $17 \%$. Treatment modalities include observation $(6 \%)$, massage $(63 \%)$, antibiotics $(77 \%)$, and surgical intervention (23\%). Massage does appear to reduce the likelihood of requiring surgical intervention however this is not statistically significant. Those patients with red lumps are more likely to have dacryocystitis and require subsequent surgical intervention $(P=0.05)$. There have only been 2 recurrences reported.

Congenital dacryocystocele is a rare presentation in the newborn. One study reports congenital dacryocystoceles are present in 1 per 3884 live births, ${ }^{11}$ but our study suggests an incidence of 1 in 18597 live births in the UK. It is possible that some cases resolved prior to reporting which could explain the difference but under reporting it is unlikely given this was a prospective study. There is a female preponderance to this condition reported in our study, which is consistent with other reports. ${ }^{7,10,11,17}$ This study found congenital dacryocystocele is more common in Caucasians, and are predominantly unilateral consistent with other reports. 7,11,18,19 Dacryocystitis complicated the condition in $49 \%$ of the patients in this study group but has been reported in up to $75 \%$ of patients in other studies. ${ }^{8}$ Signs of nasal obstruction appear relatively uncommon $(17 \%)$ with evidence of intranasal cyst extension in $100 \%$ of those cases undergoing endoscopy, consistent with a study by Levin et $a l^{16}$ Patients with uncomplicated dacryocystocele responded well to conservative measures including massage and antibiotic therapy (86\%), with only $14 \%$ requiring surgical intervention. This finding is in keeping with other reports that advocate initial conservative measures for uncomplicated dacryocystocele. $6,7,12,18,28$ This study reports a higher incidence of surgical intervention in those cases complicated by dacryocystitis compared to dacryocystocele alone (29 vs 14\%), however this is not statistically significant. It is noteworthy that $71 \%$ of patients with dacryocystitis responded to antibiotics alone. Other such studies have reported a greater need for intervention in patients with dacryocystitis. 7,8,16,23,24 There was also an increase in surgical intervention for those with nasal obstruction when compared to dacryocystoceles alone (17 vs 14\%). Normal vaginal delivery was reported in $63 \%$ of patients with $11 \%$ born via caesarean section, which has not been commented on in other studies. Due to insufficient data it is not possible to determine if the mode of delivery was related to the development of dacrocystitis or rather a reflection that most children in the UK are born via normal vaginal delivery.

This study was not designed to answer the questions of when is the best time to intervene surgically? or what is the most appropriate method of surgical intervention? The results suggest that uncomplicated dacryocystoceles are treated conservatively, and those complicated with dacryocystitis are treated initially with antibiotics followed by probing or endonasal decompression of cysts if it fails to resolve.

This study was a prospective study in the United Kingdom. The response rate to questionnaires was in the region of $71 \%$ and therefore there is missing data for 14 responses. As with any reporting system it is possible that some cases may not have been reported and hence the incidence may be higher than that reported in our study. This study also assumes that all cases of dacryocystocele will present to an ophthalmologist, where as in reality some cases may have been managed by other medical professionals or spontaneously resolved prior to review.

\section{Conclusions}

Congenital dacryocystocele is a rare presentation that can have serious consequences for the newborn if complicated by infection or nasal obstruction. They are unilateral in the majority of cases. Dacryocystitis appears to be a common complicating factor with almost half of cases developing signs of infection. Early digital massage of the lump appears to be protective however this result is not statistically significant. Conservative management appears to be sufficient in the majority of uncomplicated cases however those complicated by infection do appear more likely to require additional intervention. Due to the serious nature of the condition it is recommended that those cases that do not respond to prompt conservative measures be referred to an appropriate centre for review by a paediatric ophthalmologist. A general paediatrician should also assess these infants, as the signs of respiratory distress due to nasal obstruction may be subtle.

\section{Summary}

What was known before

- Congenital dacryocystocele is a rare presentation.

- Predominately unilateral.

- Can be complicated by dacryocystitis and respiratory compromise.

What this study adds

- Incidence of 1:18 597 cases in the United Kingdom.

- Cases complicated by dacryocystitis and respiratory compromise are more likely to require surgical intervention.

- Cases with dacryocystitis may resolve with antibiotic treatment alone. 


\section{Conflict of interest}

The authors declare no conflict of interest.

\section{Acknowledgements}

We thank the consultant ophthalmologists who contributed to this study through reporting cases of congenital dacryocystocele. We thank those who took the time to repeat the initial and follow-up questionnaire. We thank the Children and Young Peoples Research Network for contributing funding to assist in the carrying out of this study. We acknowledge the role of the British Ophthalmological Surveillance Unit, particularly Mr Barny Foot, the scientific coordinator for BOSU and the contributions of Mrs Tina McDonald who provided secretarial assistance.

\section{References}

1 Ffookes O. Dacryocystitis in infancy. Br J Ophthalmol 1962; 46: 422-434.

2 Cassady J. Dacryocystitis in infancy. Am J Ophthalmol 1948; 31: 773-780.

3 Maini R, MacEwan C, Young JD. The natural history of epiphora in childhood. Eye (Lond) 1998; 12(pt4): 669-671.

4 MacEwan C, Young JD. Epiphora during the first year of life. Eye (Lond) 1991; 5(pt5): 596-600.

5 Shashy RG, Durairaj VD, Holmes JM, Hohberger GG, Thompson DM, Kasperbauer JL. Congenital dacryocystocoele associated with intranasal cysts: diagnosis and management. Laryngoscope 2003; 113: 37-40.

6 Harris G, DiClementi D. Congenital dacryocystocele. Arch Ophthalmol 1982; 100: 1763-1765.

7 Lueder GT. The association of neonatal dacryocystoceles and infantile dacryocystitis with nasolacrimal duct cysts (An american ophthalmological society thesis). Trans Am Ophthalmol Soc 2012; 110: 74-93.

8 Mansour AM, Cheng KP, Mumma JV, Stager DR, Harris GJ Patrinely JR et al. Congenital dacryocele. A collaborative review. Ophthalmol 1991; 98: 1744-1751.

9 Leonard DS, O'Keefe M, Rowley H, Hughes JP. Neonatal respiratory distress secondary to bilateral intranasal dacryocystocoeles. Int J Pediatr Otorhinolaryngol 2008; 72(12): 1873-1877.

10 Wong RK, VanderVeen DK. Presentation and management of congenital dacryocystocoele. Pediatrics 2008; 112(5): e1108-e1112.

11 Shekunov J, Griepentrog GJ, Diehl NN, Mohney BG. Prevalence and clinical characteristics of congenital dacryocystocoele. J AAPOS 2010; 14(5): 417-420.
12 Schnall B, Christian CJ. Conservative treatment of congenital dacryocele. J Pediatr Ophthalmol Strabismus 1996; 98: 1744-1751.

13 Edmond J, Keech RV. Congenital nasolacrimal sac mucocele associated with respiratory distress. J Pediatr Ophthalmol Strabismus 1991; 28(5): 287-289.

14 Castillo M, Merten DF, Weissler MC. Bilateral nasolacrimal duct mucocele, a rare cause of respiratory distress: CT findings in two newborns. Am J Neuroradiol 1993; 14: 1011-1013.

15 Paysse EA, Coats DK, Bernstein JM, Go C, de Jong AL. Management and complications of congenital dacryocele with concurrent intranasal mucocele. J AAPOS 2000; 4(1): $46-52$.

16 Levin AV, Wygnanski-Jaffe T, Forte V, Buckwalter JA, Buncic JR. Nasal endoscopy in the treatment of congenital lacrimal sac mucoceles. Int J Pediatr Otorhinolaryngol 2003; 67: 255-261.

17 Dagi LR, Bhargava A, Melvin P, Prabhu SP. Associated signs, demographic characteristics and management of dacryocystocele in 64 infants. J AAPOS 2012; 16(3): 255-260.

18 Sullivan TJ, Clarke MP, Morin JD, Pashby RC. Management of congenital dacryocystocele. Aust N Z J Ophthalmol 1992; 20: 105-108.

19 Becker B. The treatment of congenital dacryocystocele. Am J Ophtalmol 2006; 142: 835-838.

20 Sepulveda W, Wojakowski AB, Elias D, Otaño L, Gutierrez J. Congenital dacryocystocele: prenatal 2- and 3- dimensional sonographic findings. J Ultrasound Med 2005; 24: 225-230.

21 Rogister F, Goffart Y, Daele J. Management of congenital dacryocystocele: report of 3 clinical cases. B-ENT 2016; 12(1): $83-88$.

22 Roy D, Guevara N, Santini J, Castillo L. Endoscopic marsupialization of congenital duct cyst with dacryocoele. Clin Otolaryngol 2002; 27: 167-170.

23 Pollard ZF. Treatment of acute dacryocystitis in neonates. J Pediatr Ophthalmol Strabismus 1991; 28: 341-343.

24 Cavazza S, Laffi GL, Lodi L, Tassinari G, Dall'Olio D. Congenital dacryocystocele: diagnosis and treatment. Acta Otorhinolaryngologica italica 2008; 28: 298-301.

25 Campolattaro BN, Lueder GT, Tychsen L. Spectrum of pediatric dacryocystitis: medical and surgical management of 54 cases. J Pediatr Ophthalmol Strabismus 1997; 34(3): 143-153.

26 Baskin DE, Reddy AK, Chu YI, Coats DK. The timing of antibiotic administration in the management of infant dacryocystitis. Journal of AAPOS 2008; 12(5): 456-458.

27 Eippert GA, Burnstine RA, Bates JH. Lacrimal duct probing induced bacteremia: Should children with congenital heart defects receive antibiotic prophylaxis? J Pediatr Ophthalmol Strabismus 1998; 35: 38-40.

28 Levy NS. Conservative management of congenital amniotocele of the nasolacrimal sac. J Pediatr Ophthalmol Strabismus 1979; 16: 254-256. 